\title{
Determinant factors of the difference between self-reported weight and measured weight among Japanese
}

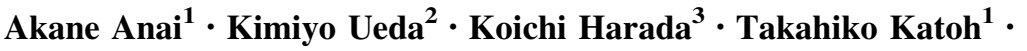 \\ Kumiko Fukumoto ${ }^{4} \cdot$ Chang-Nian Wei $^{1}$
}

Received: 4 June 2015/ Accepted: 10 August 2015/Published online: 8 September 2015

(C) The Japanese Society for Hygiene 2015

\begin{abstract}
Objectives To assess the difference between self-reported and measured weight values in Japanese men and women and to determine the underlying determinants of the differences between self-reported and measured values.

Methods The data were collected from 363 general Japanese individuals aged 16-88 years living in Kumamoto prefecture. Participants completed a self-administered questionnaire designed for this study with selfreported weight and height values. Measured weight and height were measured immediately after questionnaire completion. Paired $t$-tests identified differences between self-reported and measured values by sex. Multiple-stepwise regression analysis examined the independent variables' effects on the differences between self-reported and measured weights.

Results Significant differences were found between selfreported and measured values for both sexes $(p<0.001)$. There was a significant negative relationship between the difference in an individual's self-reported and measured weight in each sex, with higher measured weight

Akane Anai

akanan07@gmail.com

1 Department of Public Health, Faculty of Life Sciences, Kumamoto University, 1-1-1 Honjou, Kumamoto 860-8556, Japan

2 Department of Community Health Nursing, School of Health Science, Kumamoto University, Kumamoto, Japan

3 Department of Medical Technology, Faculty of Health Science, Kumamoto Health Science University, Kumamoto, Japan

4 Kyushu University of Nursing and Social Welfare, Tomio, Tamana, Japan
\end{abstract}

individuals more likely to underestimate their weight. Multiple-stepwise regression analysis models explained $12.1 \% \quad(p<0.01), \quad 11.3 \% \quad(p<0.01)$, and $5.6 \%$ $(p<0.01)$ of the variance in all participants, men, and women, respectively. Significant effects were found for age, weight measurement frequency, and measured weight in total participants, weight measurement frequency, and measured weight for men, and age for women.

Conclusions In this study, the mean absolute value of the weight and height variances proved the unreliability of self-reported weight and height values. This study's findings suggest self-reported weight inaccuracy especially for obese populations. This should be adjusted when using it in epidemiological studies and healthcare planning.

Keywords Obesity - Self-reported weight (SR-weight) . Measured weight (M-weight) · Self-reported height (SRheight) $\cdot$ Measured height (M-height)

\section{Introduction}

Obesity is defined by the Japan Society for the Study of Obesity as a BMI of 25 or above. Obesity has been identified as an important risk factor for various diseases and mortality [1, 2]. In Europe, 30-80 \% of adults are overweight or obese with rising secular trends [3, 4]. Compared to Western nations, extreme obesity (over BMI 30) is rare in Japan, and the prevalence of obesity is thought to be lower than that in Europe and the United States. However, the proportion of obese men and women in Japan has increased significantly compared to that 20 years previously. Obesity has decreased in the 40-60-year age group for women, while the incidence of obesity in the 20-60 year age group for men is currently over $30 \%$, 
compared to that 10 years ago [5]. Moreover, obese Asian populations have higher cardiovascular risk than Western populations [6]. Height and weight compose the most commonly used measurement, body mass index (BMI), in clinical practice and research. BMI, a key index for relating body weight to height, is a person's weight in kilograms $(\mathrm{kg})$ divided by their height in meters (m) squared. BMI can be used to assess obesity, nutritional status, physical activity, and overall health [7].

Weight and height data are frequently obtained by selfadministered questionnaires. These self-reported weight (SR-weight) and self-reported height (SR-height) values are used in epidemiological studies, especially large numbers population-base cohort studies. Some populationbased cohort study conducted in Japan mainly obtained weight and height data by self-reported data. For examples, the Japan Public Health Center-based Prospective Study [8], the Miyagi Cohort Study [9], the Japan Collaborative Study (JACC) [10], and the Ohsaki National Health Insurance Cohort Study [11], these studies include more than 30,000 participants and they used self-reported data to calculate BMI [12-15]. SR-weight is widely acknowledged to be a valid measure [16-21]. Many previous studies have investigated the accuracy of self-reported values; however, the results were discordant $[16,17,22-25]$. Two studies were reported in Japan. One was with 368 young Japanese women who had eating disorders [18] and the other was with 35-64-year-old Japanese workers [19]. These studies reported that SR-weight and SR-height values were valid measures $[18,19]$. However, these are the only two reports in Japan and their age and gender are limited. Moreover, they are not determined the underlying determinants of the difference.

The purpose of this study was to assess the difference between self-reported and measured weight and height values in Japanese men and women and to determine the underlying determinants of the difference.

\section{Methods}

\section{Study subjects and questionnaire}

From June 2013 to August 2013, a cross-sectional research method was used to collect data from 363 general Japanese individuals aged 16-88 years living in Kumamoto prefecture. Researchers distributed questionnaires on the day of measurement. Questionnaires were distributed to upper aged 16 years who could understand questionnaire. To ensure anonymity, no names were required on the questionnaires. Participants were asked to complete a self-administered questionnaire specifically designed for the study and to have their weight and height measured. Questionnaires were returned once the weight and height measurements were taken. The data collected were measured by us. And so the participants did not revise their self-reported value prior returning the questionnaires to us.

The first part of the questionnaire included demographic questions (sex, age, and occupation), and Table 1 lists the demographic data for each of these variables. Participants reported their weight (SR-weight) and height (SR-height), which were used to calculate the self-reported body mass index (SR-BMI). Measured body weight (M-weight) and measured height (M-height) were determined using a digital body weight scale (HBF-201, OMRON, Japan) and digital height meter (DSN-90, KDS, Japan) without shoes and with light indoor clothing in order to calculate their measured body mass index (MBMI). BMI $\left(\mathrm{kg} / \mathrm{m}^{2}\right)$ was calculated by dividing weight (kg) by height $(\mathrm{m})$ squared. An obesity classification system [26] was used to categorize participants according to BMI: underweight $\left(<18.5 \mathrm{~kg} / \mathrm{m}^{2}\right)$; normal weight $\left(18.5-24.9 \mathrm{~kg} / \mathrm{m}^{2}\right)$; overweight $\left(25.0-29.9 \mathrm{~kg} / \mathrm{m}^{2}\right)$; and obesity $\left(\geq 30 \mathrm{~kg} / \mathrm{m}^{2}\right)$. These cut-off points reflect prevailing international public health directives such as those from the 2000 Dietary Guidelines for Americans and the World Health Organization [27, 28].

The second part of the questionnaire asked seven questions on self-rated weight status, chronic health conditions, weight measurement frequency, body weight scale ownership, and perceived health status. Self-rated weight status (Q4) was measured using the question, "Do you currently consider yourself much too thin, a little too thin, just right, a little too fat, or much too fat?" [22]. The response was rated on a five-point scale from one (тисh too thin) to five (much too fat). Chronic health conditions or symptoms (Q5) were based on a multi-selection item using a two-point scale $(0$, no; 1 , yes) regarding high blood pressure, diabetes mellitus, high low-density lipoprotein cholesterol level, other conditions (with space to provide details), and no complaints. Weight measurement frequency (Q6) was based on the selected response items "every day (1)," "once a week (2)," "once a month (3)," "once every 6 months (4)," "once a year (5)," or "never do (6)." Status of weight scale ownership (Q7) was measured with a two-point selection item ( 0 , no; 1 , yes). Location for measuring body weight (Q8) was based on answers to "Where do you usually measure your body weight?" Multi-selection response items were "at home," "at work place," and "at the hospital." Perceived health status (Q9) was measured by response to the question, "All in all, would you say your health is excellent (4), good (3), fair (2), or poor (1)?" [29, 30]. Health practice status (Q10) was based on Breslow's seven health practices: [31-33] never smoking cigarettes, regular physical activity, 

demographics
Table 1 Participant

\begin{tabular}{llcr}
\hline Variable & Categories & Men, $n(\%)$ & Women, $n(\%)$ \\
\hline \multirow{2}{*}{ Age (years) } & & $199(54.8)$ & $164(45.2)$ \\
Body mass index $\left(\mathrm{kg} / \mathrm{m}^{2}\right)$ & $16-39$ & $108(37.2)$ & $110(50.5)$ \\
& $\geq 40$ & $91(62.8)$ & $54(49.5)$ \\
& $<18.4$ & $6(3.0)$ & $17(10.4)$ \\
& $18.5-24.9$ & $136(68.3)$ & $130(79.3)$ \\
Occupation & $25.0-29.9$ & $50(25.1)$ & $15(9.2)$ \\
& $\geq 30.0$ & $7(3.5)$ & $2(1.2)$ \\
& Student & $45(22.6)$ & $72(43.9)$ \\
& Company employee & $115(57.8)$ & $42(25.6)$ \\
& Agriculture & $3(1.5)$ & $3(1.8)$ \\
& Housewife & $0(0.0)$ & $16(9.8)$ \\
& Unemployed & $11(5.5)$ & $6(3.7)$ \\
& Other & $25(12.6)$ & $25(15.2)$ \\
\hline
\end{tabular}

\section{Results}

regularly, maintaining proper weight, eating breakfast, and not eating between meals. The health practice score represents the number of present health practices $(0-7)$ and has shown a clear inverse relationship with physical health status (Table 2).

This study was conducted after receiving approval from the Ethics Committee of Kumamoto University Faculty of Life Sciences on April 23, 2013 (Approval No. 644) and obtaining informed consent from all participants in written form. This study was performed in accordance with the Declaration of Helsinki.

\section{Statistical analysis}

Data were analyzed using the Statistical Package SPSS Version 20. Paired $t$-tests were conducted to identify significant sex differences and differences between (a) SRweight and M-weight, (b) SR-height and M-height, and (c) SR-BMI and M-BMI. Chi-square tests were used to compare percentages of men and women participants who reported "yes" or "no" for employing health practices, weight measurement frequency, weight scale ownership, and perceived health status. Pearson's correlation analyses were used to determine the relationship between M-weight and the differences between SR-weight and M-weight (SRweight subtracted from M-weight) for each sex. Multiple regression analyses were used to examine the effects of the independent variables of age, employment, SR-weight status, chronic conditions, weight measurement frequency, health practices, perceived health status, and M-weight on the differences between SR-weight and M-weight (SRweight subtracted from M-weight). A $p$ value of 0.05 was regarded as significant.

\section{Differences between self-reported and measured values}

Based on SR-weight and SR-height, $76.3 \%$ of participants (men, $72.9 \%$; women, $81.1 \% ; p<0.01$ ) had normal BMI, $6.9 \%$ (men, $4.0 \%$; women, $10.4 \%$; $p<0.05$ ) were underweight, $14.6 \%$ (men, $20.6 \%$; women, $7.3 \%$; $p<0.01$ ) were overweight, and $2.2 \%$ (men, $3.0 \%$; women, $1.2 \% ; p>0.05$ ) were obese. A high proportion of participants had normal weight, but only $33.3 \%$ of participants (men, $32.2 \%$; women, $34.8 \% ; p>0.05$ ) considered their body weight "just right." Of the rest, $11.9 \%$ (men, $14.1 \%$; women, 9.2\%; $p>0.05$ ) considered themselves "a little too thin," $3.0 \%$ (men, $3.0 \%$; women, $3.0 \% ; p>0.05)$ considered themselves "much too thin," $35.8 \%$ (men, $34.2 \%$; women, $37.8 \% p>0.05$ ) considered themselves "a little too fat," and $16.0 \%$ (men, $16.6 \%$; women, $15.2 \% ; p>0.05$ ) considered themselves "much too fat."

Table 3 shows differences between SR-weight and M-weight (M-weight subtracted from SR-weight) for each sex. Paired $t$-tests revealed significant differences between SR-weight and M-weight overall and by sex. Significant differences were also observed for SR-BMI and M-BMI.

Significant correlations were found between self-reported and measured values in weight, height, and BMI for both men and women (Table 3). Both men and women significantly underestimated their weight (Table 3). Men significantly overestimated and women significantly underestimated their height. Although the difference between SR-height and M-height was statistically significant, the mean difference was very small. 
Table 2 Variables in the analysis of differences of weight between SR-weight and M-weight

\begin{tabular}{|c|c|c|}
\hline Variable & Categories & Remarks \\
\hline \multicolumn{3}{|l|}{ Demographic status } \\
\hline Sex & Female/male & \\
\hline Age & Years & \\
\hline M-Body weight & $\mathrm{kg}$ & $\begin{array}{l}\text { Based on measured values by body weight scales by } \\
\text { reasearchers }\end{array}$ \\
\hline SR-Body weight & $\mathrm{kg}$ & Based on their self-reported values \\
\hline M-height & $\mathrm{cm}$ & $\begin{array}{l}\text { Based on measurred values by stadiometer by } \\
\text { reasearchers }\end{array}$ \\
\hline SR-height & $\mathrm{cm}$ & Based on their self-reported values \\
\hline M-BMI & $\mathrm{kg} / \mathrm{m}^{2}$ & $\begin{array}{l}\text { Based on measured body weight values to calculate by } \\
\text { M-weight and M-height by researchers. It was divided } \\
\text { into four categorical (underweight/normal weight/ } \\
\text { overweight/obesity) }\end{array}$ \\
\hline SR-BMI & $\mathrm{kg} / \mathrm{m}^{2}$ & $\begin{array}{l}\text { Based on their report, body weight and height values } \\
\text { calculated by researchers. It was divided into four } \\
\text { categorical (underweight/normal weight/overweight/ } \\
\text { obesity) }\end{array}$ \\
\hline Self-rated weight status (Q4) & $\begin{array}{l}\text { Much too thin, a little too thin, just } \\
\text { right, a little too fat, or much too fat }\end{array}$ & $\begin{array}{l}\text { "Do you consider yourself now much too thin, a little } \\
\text { too thin, just right, a little too fat or much too fat?" [8] }\end{array}$ \\
\hline $\begin{array}{l}\text { Subjective chronic condition or } \\
\text { symptoms (Q5) }\end{array}$ & $\begin{array}{l}\text { Diabetes mellitus, HLDL-C, other, } \\
\text { and non-complaints }\end{array}$ & Based on their self-report \\
\hline $\begin{array}{l}\text { Weight measurement } \\
\text { frequency (Q6) }\end{array}$ & $\begin{array}{l}\text { Every day, once/week, once/month, } \\
\text { once/half year, once/year, or never } \\
\text { do }\end{array}$ & Based on their self-report \\
\hline $\begin{array}{l}\text { Possessing a weight scale } \\
\text { status (Q7) }\end{array}$ & Yes/no & \\
\hline $\begin{array}{l}\text { Location for measuring body } \\
\text { weight }(\mathrm{Q} 8)\end{array}$ & At home, at work place, at the hospital & "Where do you usually measure your body weight?" \\
\hline Perceived health (Q9) & Excellent/good/fair/poor & $\begin{array}{l}\text { "All in all, would you say your health is excellent, } \\
\text { good, fair, or poor?" Responses were rated on 4-point } \\
\text { scale from" "Excellent (4) to Poor }(1) "[22,23]\end{array}$ \\
\hline Health practices (Q10) & & Based on Breslow's seven health practices [19-21] \\
\hline $7-8 \mathrm{~h}$ sleep/day & Yes/no & \\
\hline Maintaining proper weight & Yes/no & \\
\hline Moderate or no use of alcohol & Yes/no & \\
\hline Regular activity & Yes/no & \\
\hline Not eating between meals & Yes/no & \\
\hline Eating breakfast & Yes/no & \\
\hline Never smoking cigarettes & Yes/no & \\
\hline
\end{tabular}

\section{Health practices}

The data showed differences in SR-weight and M-weight according to whether participants maintained proper weight, one of Breslow's seven health practices. Significant differences were found between the weights of participants who reported maintaining proper weight and those who did not in both SR-weight (maintaining, $57.7 \pm 8.4 \mathrm{~kg}$; did not, $64.4 \pm 12.7 \mathrm{~kg} ; p<0.001$ ), and M-weigh (maintaining, $58.4 \pm 8.6 \mathrm{~kg}$; did not, $65.1 \pm 12.9 \mathrm{~kg} ; p<0.001)$. The absolute values of SR-weight minus M-weight were not significantly different between male or female participants who reported maintaining proper weight $(1.19 \pm 0.95 \mathrm{~kg})$ and did not $(1.21 \pm 1.01 \mathrm{~kg})$.

\section{Weight measurement frequency}

Men reported $10.1 \%$ "every day," $22.1 \%$ "once a week," $33.7 \%$ "once a month," $13.1 \%$ "once every 6 months," $10.1 \%$ "once a year," and $11.1 \%$ "never do" percentages of weight measurement frequency. For women, $30.5 \%$ answered "every day," $27.4 \%$ “once a week," $23.2 \%$ "once a month," $12.2 \%$ "once every 6 months," $3.7 \%$ "once a year," and $3.0 \%$ "never do." Most men answered 
Table 3 Descriptive statistics and correlations of participants' measured and self-reported weights, heights, and BMIs

\begin{tabular}{|c|c|c|c|}
\hline Statistics & Weight $(\mathrm{kg})$ & Height $(\mathrm{cm})$ & BMI $\left(\mathrm{kg} / \mathrm{m}^{2}\right)$ \\
\hline \multicolumn{4}{|l|}{ Men $(n=199)$} \\
\hline Measured value $(\mathrm{M} \pm \mathrm{SD})$ & $68.4 \pm 9.9$ & $170.6 \pm 5.6$ & $23.5 \pm 3.1$ \\
\hline Self-reported value $(M \pm S D)$ & $67.7 \pm 9.6^{\mathrm{b}, *}$ & $170.8 \pm 5.6^{\mathrm{b}, *}$ & $23.2 \pm 2.9^{\mathrm{b}, *}$ \\
\hline Pearson's correlation coefficient & $0.974 * *$ & $0.980 * *$ & $0.962^{* *}$ \\
\hline Mean difference ${ }^{a}$ & -0.7 & 0.01 & -0.3 \\
\hline Range & -4.0 to 5.0 & -4.3 to 7.5 & -1.9 to 2.6 \\
\hline $95 \%$ confidence interval & -1.07 to -0.45 & $0.00-0.31$ & -0.42 to -0.19 \\
\hline Mean absolute value of the difference ${ }^{a}$ & 1.45 & 0.75 & 0.57 \\
\hline $95 \%$ confidence interval & $1.20-1.71$ & $0.64-0.87$ & $0.47-0.67$ \\
\hline \multicolumn{4}{|l|}{ Women $(n=164)$} \\
\hline Measured value $(\mathrm{M} \pm \mathrm{SD})$ & $53.4 \pm 6.8$ & $157.7 \pm 6.0$ & $21.5 \pm 2.8$ \\
\hline Self-reported value $(\mathrm{M} \pm \mathrm{SD})$ & $52.8 \pm 6.5^{\mathrm{b}, *}$ & $157.5 \pm 5.9^{\mathrm{b}, *}$ & $21.3 \pm 2.6^{\mathrm{b}, *}$ \\
\hline Pearson's correlation coefficient & $0.986 * *$ & $0.989 * *$ & $0.979^{* *}$ \\
\hline Mean difference ${ }^{a}$ & -0.67 & -0.16 & -0.23 \\
\hline Range & -6.2 to 2.5 & -2.7 to 3.2 & -2.8 to 1.3 \\
\hline $95 \%$ confidence interval & -0.85 to -0.49 & -0.30 to -0.03 & -0.32 to 0.14 \\
\hline Mean absolute value of the difference ${ }^{a}$ & 1.01 & 0.68 & 0.44 \\
\hline $95 \%$ confidence interval & $0.88-1.15$ & $0.60-0.77$ & $0.37-0.51$ \\
\hline
\end{tabular}

$B M I$ Body mass index

${ }^{a}$ Differences were obtained by subtracting the self-reported value from the measured value. A negative value reflects underestimating and a positive value reflects overestimating

${ }^{\mathrm{b}}$ Significant difference between self-reported and measured values

$* p<0.05, * * p<0.01$ "once a month," and most women answered "every day." The percentage of weight measurement frequency in women was significantly higher than that in men $(p<0.001)$.

By age decade from 20 to 70 and older, the percentages of men's weight scale ownership were $21.5,20.1,16.6$, $15.6,10.1,11.1$, and $3.5 \%$, respectively, and for women $17.1,29.3,14.0,9.8,6.7,7.3$, and $4.3 \%$, respectively. The highest percentages were for those in their 20 and $30 \mathrm{~s}$. Women had a significant higher percentage of weight scale ownership ratio than men (women, $88.4 \%$; men, $78.4 \%$; $p<0.01)$.

There were no statistical significant differences between SR-weight and M-weight among the occupations. There were no statistical significant differences between SRweight minus M-weight in weight scale ownership. There was no statistical difference between weight measurement frequency and maintaining proper weight for either sex.

\section{Simple correlation analysis}

A significant correlation was observed for the difference between subtracted M-weight from SR-weight and M-weight in each sex ( $r=-0.258$ for men, $r=-0.338$ for women, $p<0.001)$. The data showed a significant negative relationship between individual's SR-weight and their actual weight (M-weight), with higher M-weight individuals more likely to underestimate their weight (Fig. 1).

\section{Multiple-stepwise regression analysis}

Multiple-stepwise regression analyses were performed to determine which independent variables were good predictors of the differences between M-weight subtracted from SR-weight. Age, self-rated weight status, chronic conditions, weight measurement frequency, M-weight, M-height, health practices, and perceived health status were used as independent variables, and the absolute value differences between M-weight subtracted from SR-weight were used as dependent variables. For those variables in the regression model, coefficient of determination in the models explained $12.1 \%(p<0.01), 11.3 \%(p<0.01)$, and $5.6 \%(p<0.01)$ of the variance in all participants, men, and women, respectively (Table 4).

Several highly significant correlations for the independent variables were found. Age, weight measurement frequency, and M-weight were significant for all participants; weight measurement frequency and M-weight were significant in men; and age was significant in women. No significant effects were observed for self-rated weight 


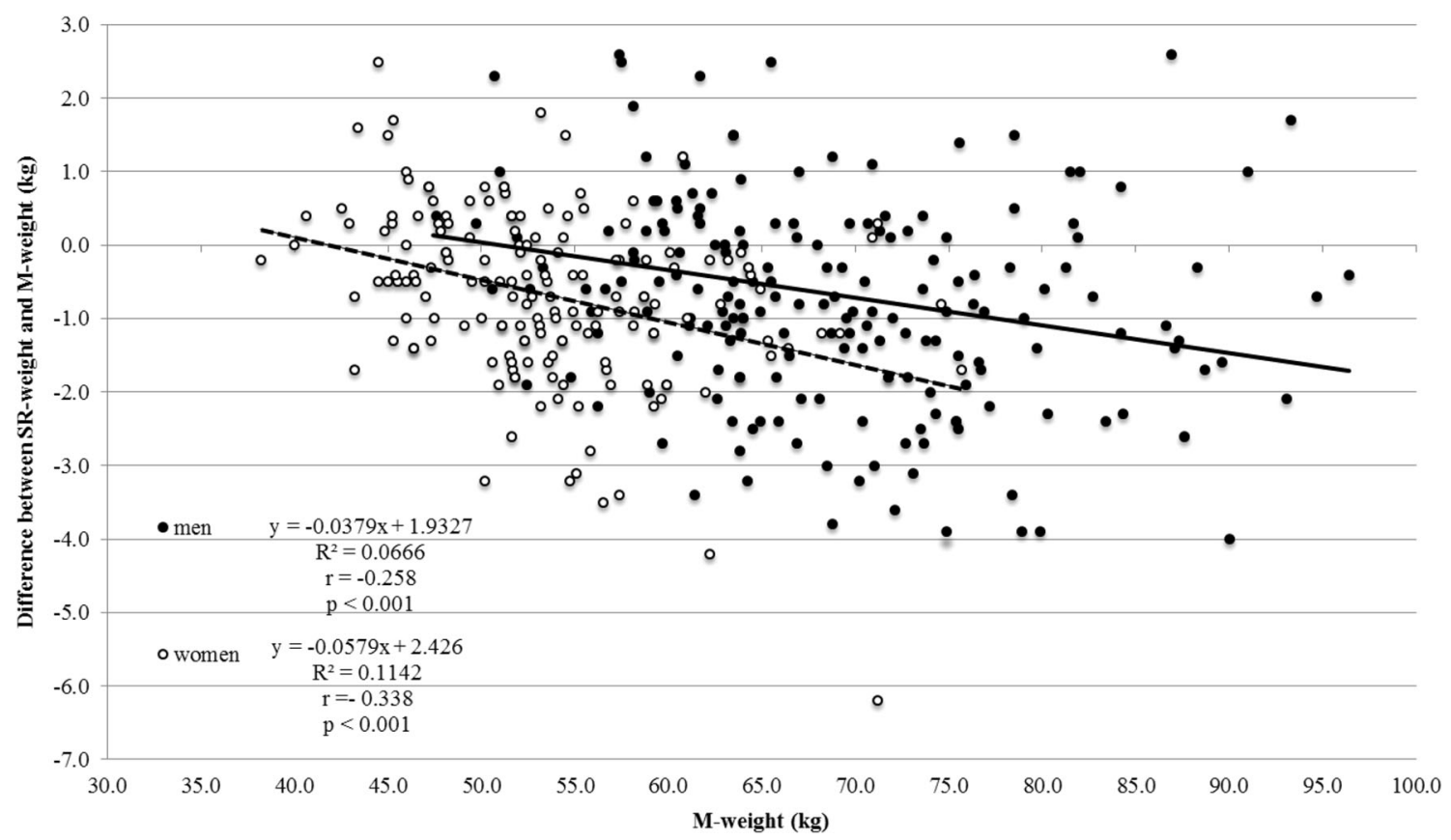

Fig. 1 Relationship between M-weight and the differences between SR-weight and M-weight for men and women

Table 4 Multiple-stepwise analyses of absolute value differences between SR-weight and M-weights for independent variables

\begin{tabular}{llll}
\hline Variable & Total & Male & Female \\
\hline Age & $0.164^{* *}$ & - & $0.237^{* *}$ \\
Weight measurement frequency & $0.219^{* * *}$ & $0.246^{* * *}$ & - \\
M-weight & $0.184^{* * *}$ & $0.162^{*}$ & - \\
$R^{2}$ & $0.121^{* *}$ & $0.113^{* *}$ & $0.056^{* *}$ \\
\hline
\end{tabular}

$* p<0.05, * p<0.01, * p<0.001$

status, chronic health condition, health practices, perceived health status, or M-height on differences of absolute values between SR-weight and M-weight.

\section{Discussion}

BMI can be used to assess obesity, nutritional status, physical activity, and overall health [7]. Obesity is defined by the Japan Society for the Study of Obesity as a BMI of 25 or above. Although BMI is considered a crude estimate of body fat given that body weight includes fat and muscle tissue, it is an internationally accepted obesity assessment for adults because it correlates well with body fat [24, 34]. BMI is calculated as body weight $(\mathrm{kg})$ divided by height (m) squared. In this study, body weight was based on respondents SR-height and SR-weight. SR-weight is widely acknowledged to be a valid measure [16-21]. In fact, this study confirmed previously reported results [16$18,20,23-25,35,36]$ that SR-height and SR-weight highly correlate with $\mathrm{M}$-height and $\mathrm{M}$-weight in both men and women. In this study, a higher variance was found in weight and height between self-reported and actual measured values in men and women. The differences between self-reported values and measured values were statistically significant and the mean value variance was higher than that in previous Japanese studies [18, 19].

Simple correlation analysis in Fig. 1 showed a significant negative relationship between the differences of individual's SR-weight minus M-weight and their actual weight (M-weight). Both men and women with higher $\mathrm{M}$-weight individuals were more likely to underestimate their weight. Multiple-stepwise regression analyses were performed to identify which independent variables were good predictors of the differences between SR-weight and M-weight. The present data confirmed a significant positive age effect for this difference in women only. Although many previous studies have investigated the association between age and bias in self-reported values, their results were not always concordant [16, 18, 21, 23, 24, 36-40]. In addition, sex differences were found in certain independent variables; weight measurement frequency and $\mathrm{M}$-weight had a significant positive effect only in men. The results suggest that those who measure their body weight frequently understand their proper body weight well.

In this study, differences in body weight by whether participants maintained proper weight (one of Breslow's seven health practices) were also observed. Average 
M-weight of participants not maintaining proper weight was significantly higher than that of participants who maintained proper weight for both men and women. Especially for men, the average M-BMI of participants who did not maintain proper weight was very close to $25 \mathrm{~kg} / \mathrm{m}^{2}$, which is classified as overweight $\left(24.7 \pm 3.5 \mathrm{~kg} / \mathrm{m}^{2}\right)$.

This study had several limitations. First, body weight is affected by many factors, the most important of which is metabolic rate related to muscular exercise. Determining metabolic rate during daily life activities is difficult because several factors affect metabolic rate (i.e., muscular exertion during or just before measurement, recent food ingestion, high or low environmental temperature, height, weight, surface area, sex, age, emotional state, body temperature, circulating levels of thyroid hormones, and circulating epinephrine and norepinephrine levels) [41]. Although height and weight were measured while participants were dressed in light indoor clothing, without footwear, and after not eating or drinking for $2 \mathrm{~h}$, many other factors could not be controlled. Second, in this study sample, 66 young women were missing reported weight data. This might reflect a societal custom or tendency for young women to withhold their body weight.

Despite these limitations, the present findings suggest cautious use of SR-weight in epidemiologic study and health care services. With the growing prevalence of obesity, it is becoming increasingly important to understand estimations of actual body weight relevant to health care service relationships in order to minimize health consequences. In addition, a sex effect was observed in the difference between SR-weight and M-weight, which is consistent with recent research but warrants further exploration. Unfortunately, the sample did not include enough severely obese respondents for meaningful statistical comparison across sexes or for examination of important characteristics of body image (missing data in women).

In many studies, self-reported data were obtained days or months before the measurement, and the measured value was obtained from health check-up. In this study, self-reported weight was obtained just before the measurement that was not at the health check-up. Even though students and company employee have health check-up every year, it is usually only once a year and the time of health check-up is not same. Therefore, it is necessary to ask the time of last weight measurement in the future study.

Finally, this study's findings suggest poor reliability of SR-weight for obese and older age populations in particular. In examining the prevalence of obesity or the association of obesity with various diseases among a general population, SR-BMI should be used with caution given its tendency to be lower than the measured value.
Thus, it is recommended not only to consider these biases carefully in data interpretation, but also to adjust for them when using SR-weight in epidemiological studies and community health care planning.

Acknowledgments We would like to thank all participants in this study. We express our sincere appreciation to the staff members of the Department of Preventive and Environmental Medicine and the Department of Public Health, Faculty of Life Sciences, Kumamoto University. This work was supported in part by Program for Leading Graduate Schools "HIGO" (Health life science: Interdisciplinary and Glocal Oriented), MEXT, Japan.

\section{Compliance with ethical standards}

Conflict of interest The authors declare that they have no conflict of interest.

\section{References}

1. Hayahi R, Iwasaki M, Otani T, Wang N, Miyazaki H, Yoshiaki S, et al. Body mass index and mortality in a middle-aged Japanese cohort. J Epidemiol. 2005;15(3):70-7.

2. Kenk J, Nagel G, Ulmer H, Strasak A, Concin H, Diem G, et al. Body mass index and mortality: results of a cohort of 184,697 adults in Austria. Eur J Epidemiol. 2009;24(2):83-91.

3. WHO, Regional Office for Europe. The challenge of obesity in the WHO European Region and the strategies for response. http:// www.euro.who.int/document/E90711.pdf. Accessed 5 June 2009.

4. Knai C, Suhrcke M, Lobstein T. Obesity in Eastern Europe: an overview of its health and economic implictions. Econ Hum Biol. 2007;5:392-408.

5. Ministry of Health, Labour and Welfare, Japan. Overview of the National Health and Nutrition survey results 2011. http://www. mhlw.go.jp/stf/houdou/2r9852000002q1st.html Accessed 4 Dec 2013 (in Japanese).

6. Serena L, Mien Chew C, Stefan M, Derrick H, Deurenberg-Yap M. Rationale for redefining obesity in Asians. Ann Acad Med Singapore. 2009;38:66-74.

7. Sasazuki S, Inoue M, Tsuji I, Sugawara Y, Tamakoshi A, Matsuo $\mathrm{K}$, et al. Body mass index and mortality from all causes and major causes in Japanese: results of a pooled analysis of 7 large-scale cohort studies. J Epdemiol. 2011;21(6):417-30.

8. Tsugane S, Sobue T. Baseline survey of JPHC study—design and participation rate. J Epidemiol. 2001;11:24-9.

9. Fukao A, Tsubono Y, Komatsu S, Tsuji I, Minami Y, Hisamichi S, Hosokawa T, Kawamura M, Takano A, Sugahara N, Ikeda T, Nishikori M. A cohort study on the relation of Lifestyle, personality and biologic markers to cancer in Miyagi, Japan: study design, response rate and profiles of the cohort subjects. J Epidemiol. 1995;5:153-7.

10. Ohno Y, Tamakoshi A, The JACC Study Group. Japan cpllaborative cohort study for evaluation of cancer risk sponsored by monbusho (JACC study). J Epidemiol. 2001;11:144-50.

11. Tsuji I, Nishino Y, Ohkubo T, Kuwahara A, Ogawa K, Watanabe Y, Tsubono Y, Bando T, Kanemura S, Izumi Y, Sasaki A, Fukao A, Nishikori M, Hisamichi S. A prospective cohort study on National Health Insurance Beneficiaries in Ohsaki, Miyagi Prefecture, Japan: study design, profiles of the subjects and medical cost during the first year. J Epidemiol. 1998;8:258-63.

12. Iso H, Kobayashi M, Ishihara J, Sasaki S, Okada K, Kita Y, Kokubo Y, Tsugane S. Intake of fish and $\mathrm{n} 3$ fatty acids and risk of 
coronary heart disease among Japanese. Circulation. 2006;113:195-202.

13. Takachi R, Inoue M, Ishihara J, Kurahashi N, Iwasaki M, Sasazuki S, Iso $\mathrm{H}$, Tsubono $\mathrm{Y}$, Tsugane $\mathrm{S}$. Fruit and vegetable intake and risk of total cancer and cardiovascular disease. Am J Epidemiol. 2008;167:59-70.

14. Kawai M, Minami Y, Kakizaki M, Kakugawa Y, Nishino Y, Fukao A, Tsuji I, Ohuchi N. Alcohol consumption and breast cancer risk in Japanese women: the Miyagi Cohort Study. Breast Cancer Res Treat. 2011;128:817-25.

15. Nagamura T, Kuriyama S, Kakizaki M, Sone T, Nakaya N, Ohmori-Matsuda K, Nishino Y, Fukao A, Tsuji I. Coffee consumption and the risk of oral, pharyngeal, and esophageal cancers in Japan. Am J Epidemiol. 2008;168(12):1425-32.

16. Brener ND, McManus T, Galuska DA. Reliability and validity of self-reported height and weight among high school students. J Adolesc Health. 2003;37:281-7.

17. Spencer EA, Appleby PN, Davey GK, Key TJ. Validity of selfreported height and weight in 4808 EPIC-Oxford participants. Public Health Nutr. 2002;5:561-5.

18. Nakamura K, Hoshino Y, Kodama K, Yamamoto M. Reliability of self-reported body height and weight of adult Japanese women. J Biosoc Sci. 1999;31:555-8.

19. Wad K, Tamakoshi K, Tsunekawa T, Otsuka R, Zhang H, Murata $\mathrm{C}$, et al. Validity of Self-reported height and weight in a Japanese workplace population. Int J Obes. 2005;29:1093-9.

20. Strauss RS. Comparison of measured and self-reported weight and height in a cross-sectional sample of young adolescents. Int $\mathbf{J}$ Obes Relat Metab Disord. 1999;23:904-8.

21. Bolton-Smith C, Woodward M, Tunstall-Pedoe H, Morrison C. Accuracy of the estimated prevalence of obesity from self-reported height and weight in an adult Scottish population. J Epidemiol Community Health. 2000;54:143-8.

22. Mikolajczyk RT, Maxwell AE, EIAnsari W, Stock C, Petkeviciene J, Guillen-Grima F. Relationship between perceived body weight and body mass index based on self-report height and weight among university students: a cross-sectional study in seven European countries. BMC Public Health. 2010. doi:10. 1186/1471-2458-10-40.

23. Niedhammer I, Bugel I, Bonenfant S, Goldberg M, Leclerc A. Validity of self-reported weight and height in the French GAZEL cohort. Int J Obes Relat Metab Disord. 2000;24:1111-8.

24. Giacchi M, Mattei R, Rossi S. Correction of the self-reported BMI in a teenage population. Int $\mathrm{J}$ Obes Metab Disord. 1998;22:673-7.

25. Lawlor DA, Bedford C, Taylor M, Ebrahim S. Agreement between measured and self-reported weight in older women.
Results from the Britishi Women's Heart and Health Study. Age Ageing. 2002;31:169-74.

26. Villanueva EV. The validity of self-reported weight in US adults: a population based cross-sectional study. BMC Public Health. 2001;1:11.

27. Dietary Guidelines Advisory Committee. Report of the dietary guidelines advisory committee on the dietary guidelines for Americans, 2000. Washington: US Department of Agriculture; 2000.

28. World Health Organization. Physical status: the sue and interpretation of anthropometry. Report of a WHO expert committee. WHO Tech Rep Ser 854, 1995.

29. Kaplan GA, Camacho T. Perceived health and mortality: a nineyear follow up of the human population laboratory cohort. Am J Epidemiol. 1983;117(3):292-304.

30. Idler EL, Benyamini Y. Self-rated health and mortality: a review of twenty-seven community studies. J Health Soc Behav. 1997;38(March):21-37.

31. Belloc NB, Breslow Lester. Relationship of physical health status and health practices. Prev Med. 1972;1:409-21.

32. Belloc NB. Relationship of health practices and mortality. Prev Med. 1973;2:67-81.

33. Breslow L, Enstrom J. Persistence of health habits and their relationship to mortality. Prev Med. 1980;9:469-83.

34. Epstein FH, Higgins M. Epidemiology of obesity. In: Bjorntorp P, Brodoff BN, editors. obesity. Philadelphia: JB Lippincott; 1992. p. 330-42.

35. Kuczmarski MF, Kuczmarski RJ, Najjar M. Effects of age on validity of self-reported height, weight, and body mass index: findings from the Third National Health and Nutrition Examination Survey, 1988-1994. J Am Diet Assoc. 2001;101:28-34.

36. Nawaz H, Chan W, Abdulrahman M, Larson D, Katz DL. Selfreported weight and height: implication for obesity research. Am J Prev Med. 2001;20:294-8.

37. Rowland ML. Self-reported weight and height. Am J Clin Nutr. 1990;52:1125-33.

38. Bostrom G, Diderichsen F. Socioeconomic differentials in misclassification of height, weight and body mass index based on questionnaire data. Int J Epidemiol. 1997;26:860-6.

39. Jeffery RW. Bias in reported body weight as a function of education, occupation, health and weight concern. Addict Behav. 1996;21:517-22.

40. World Health Organization. Obesity: preventing and managing the global epidemic report of a WHO consultation on Obesity. Geneva: WHO; 1997.

41. Ganong WF. Review of medical physiology. 17th ed. San Francisco: University of California San Francisco; 1987. 